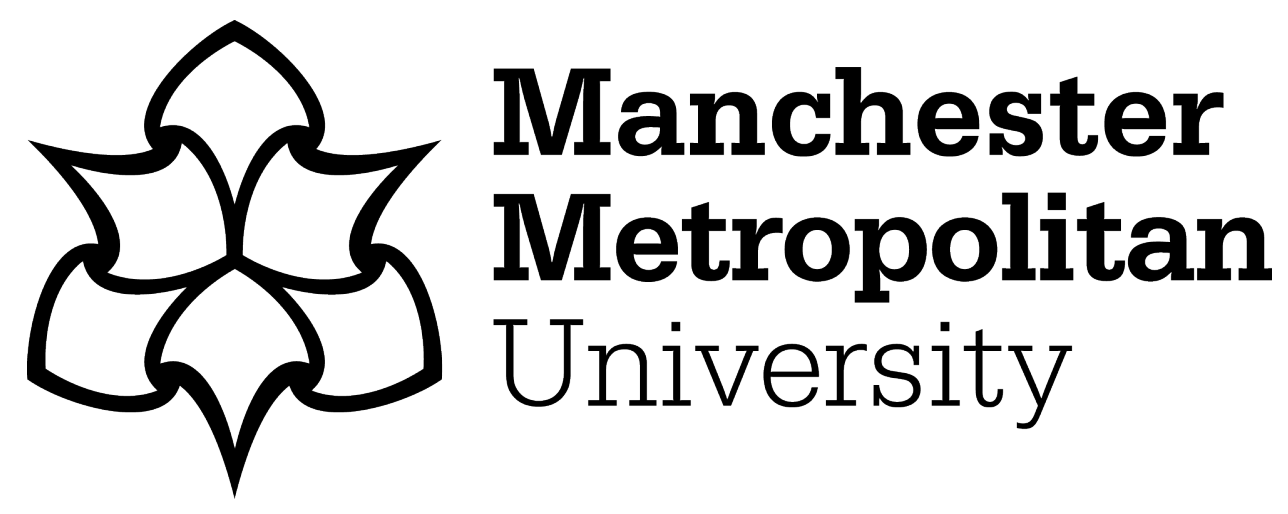

Ward, R, Howorth, M, Wilkinson, H, Campbell, S ORCID logoORCID: https://orcid.org/0000-0002-2920-7318 and Keady, J (2011) Supporting the friendships of people with dementia. Dementia, 11 (3). pp. 287-303. ISSN 1471-3012

Downloaded from: https://e-space.mmu.ac.uk/625044/

Version: Accepted Version

Publisher: Sage

DOI: https://doi.org/10.1177/1471301211421064

Please cite the published version 


\title{
Supporting the friendships of people with dementia
}

\author{
Richard Ward \\ University of Manchester/Greater Manchester West Mental Health \\ NHS Foundation Trust, UK
}

\section{Mike Howorth}

Greater Manchester West Mental Health NHS Foundation Trust, UK

\section{Heather Wilkinson}

University of Edinburgh, UK

\section{Sarah Campbell}

University of Manchester, UK

\section{John Keady}

University of Manchester/Greater Manchester West Mental Health NHS Foundation Trust, UK

\begin{abstract}
Using illustrative case examples, in this paper we explore the friendships of people with dementia in the early stages of the condition and the benefits of looking beyond the family as the 'go to' support network that practitioners tend to focus on in their work with people with dementia. The importance of participatory approaches in both research and practice for understanding the friendship experiences of people with dementia is highlighted. The case studies include a personal narrative on friendships from one of the authors, a person living with dementia. This is followed by an account of a peer support group for people with dementia where the interactions in the group are explored alongside consideration of the significance and outcomes of creating such social spaces for people with dementia. We pay particular attention to the emerging phenomenon of 'facilitated friendships' as practitioners work to support collective agency on the part of people with dementia.
\end{abstract}

\section{Keywords}

dementia, friendships, neighbourhoods, peer support, personal communities, social networks 


\section{Introduction}

In this paper, our emphasis is on the meaning and significance attached to friendships by people with dementia. We distinguish between the maintenance of existing friendships following a diagnosis of dementia and the establishment of new friendships, often with the support of 'friendship facilitators'. ${ }^{1}$ We argue that practitioners have a role to play in creating the opportunities for such relationships to develop while cautioning against relying upon too narrow or simplistic a notion of what constitutes friendship. For instance, Kutner, Brown, Stavisky, Clark, and Green (2000) who set out to explore friendship interactions and expressions of agitation among residents with dementia in care homes, defined friendships as:

'...the continued interaction of specified individuals over an extended time period. Friends were individuals who were observed to be sitting or walking with, touching, or involved in 'conversation' with a specified other resident for the majority of the observation period.'

(Kutner et al., 2000, p. 190)

Here friendships are defined according to what is knowable from the standpoint of the observer. Pragmatic definitions such as this offer a perspective on friendships from 'the outside'; they fail to adequately account for the emotional dimension that is largely beyond the reach of observational methods. We argue there is a need to recognize both the diversity and the complexities of these relationships and to acknowledge the limitations that characterize current research methods while seeking out more creative approaches that might help to explore the multi-layered and fluid nature of friendships over time.

To help illuminate such accounts, we draw upon two detailed illustrative case examples to outline different, but complementary, approaches to exploring and facilitating the friendships of people with dementia. The first case example is a personal narrative on the meaning of friendships by one of the co-authors of this paper $(\mathrm{MH})$ who lives with Alzheimer's disease and who is the coordinator of the Open Doors network ${ }^{2}$ in Salford, Greater Manchester, UK (Howorth, Riley, Drummond, \& Keady, 2011). The second case example is drawn from a recent evaluation of the 'Friends for Life' peer support project ${ }^{3}$ for people with an early and recent diagnosis of dementia in Salford, Greater Manchester. In this case example, we focus on the relational and friendship processes of one established group and the context in which these were fostered. Building on these two examples we outline why a focus upon such friendships is an important consideration for practitioners and service providers.

We begin by considering the existing literature and present an argument for expanding the current, family-centred perspectives in dementia care to encompass the broader and more diffuse range of relationships in which people with dementia live and are often embedded.

\section{Friendships literature}

Recent debate on contemporary social relationships makes any simple definition of 'friendship' problematic (Spencer \& Pahl, 2006) and indeed raises questions over how useful it is to promote a single notion of friendship or to assume its place in the hierarchies of closeness, kin and household (Roseneil, 2004). For example, research within gay and lesbian communities in the US and the UK has drawn attention to the phenomenon of 'families of choice' (Weeks, Heaphy, \& Donovan, 2001; Weston, 1991). This is where, 
often, as a result of estrangement from their family of origin, lesbians and gay men have developed their own families, comprising friends and (ex-)partners, consequently blurring the boundaries between traditional notions of friendship and family. Chosen families exemplify a broader shift to self-determinacy and relational choice in many Western societies where 'blood and legal ties [increasingly] matter less than who 'does' family' (Heaphy, 2009, p. 122). Such arguments underline that, as researchers and/or practitioners, it is important not to presume to know what significance a particular friendship holds at an individual level, nor what status it may have in comparison with other relationships in a person's life.

A central strand within the Dementia Strategy developed in the UK is emphasis placed on the role of peer support in living well with dementia (Department of Health, 2009). This rise in interest in friendships on the policy agenda in the UK also reflects the rapid pace of change to contemporary lifestyles and social arrangements. Geographically dispersed families, coupled with increases in divorce rates and the rising proportion of those living in single person households (many of whom are older women), point to the need to recognize a more varied and diverse range of relationships in which people may give or receive care and support. The neglect of friendships as a topic of investigation and scrutiny has fostered a tendency to marginalize "love, intimacy, care and sociality beyond "the family" (Roseneil \& Budgeon, 2004, p. 137). From this perspective, paying attention to friendships in the lives of people with dementia helps to de-centre the 'family' in how we picture the support available to them, and open up our thinking to alternative sources of help and social connection in people's lives as well as to understanding the support and care that people with dementia provide to others.

The emphasis on the impact of dementia on the 'caring' relationship, i.e. the relationship between family carer and person with dementia, is only one perspective on the fundamental role of relationships for the person with dementia. The majority of such literature also has a focus on the stress and other negative aspects of this relationship from the perspective of the carer but rarely from that of the person with dementia (Blieszner \& Shifflett, 1990; Charlesworth, Tzimoula, Higgs, \& Poland, 2007; Lilly, Richards, \& Buckwalter, 2003). Where more recent literature does give greater consideration to the perspective of the person with dementia, the importance of relationships remains under-acknowledged. For example, de Boer et al. (2007) highlighted the emotion-orientated and problem-orientated coping strategies that people with dementia draw on, but the understanding and role of relationships emerges from their review as under-developed with a focus on "what others think' about the person with dementia and the experience of 'imposed limitations' from other family members to their relative with dementia (p. 1028). Drawing on a 'risk' lens to understand the importance of relationships for someone with dementia, Clarke et al. (2010) highlight the area of friendships as one of the 'contested territories' that they argue are negotiated by people with dementia on a daily basis in order to make sense of living with dementia. Clearly, an understanding about how relationships are continued, re-constructed and negotiated post-diagnosis is essential to supporting positive living with dementia.

While there is little work that enhances our understanding of how people with dementia negotiate existing friendships and relationships, there is a more established body of work that focuses on 'new' friendships, usually developed through formal and informal peer support group arrangements. The understanding of the benefits of supportive relationships can be traced to the work of Snyder, Quayhagen, Shepherd, and Bower (1995) and has gathered momentum since then. The long-standing exploration of the 
positive role of support groups undertaken by Snyder and colleagues validates the importance of peer group relationships in developing coping mechanisms, trust, support and more positive identities. Offord, Hardy, Lamers, and Bergin (2006) illustrate how these new friendships form through the development of a shared understanding and experience in a support group and take on priority for the person with dementia, arguably as the stigma, fears and challenges that can be associated with existing friendships are not present. Interestingly, the proposed benefits of these new friendships based on new shared and coping experiences have been taken up in the English National Dementia Strategy implementation using peer support as a key delivery mechanism (Department of Health, 2009); we return to this point more fully in our second case example.

Many of the benefits of peer support relationships are for people still living at home. For people with dementia using formal support settings or living in care home settings a few qualitative studies illustrate the continuing importance of relationships. Williams and Roberts (1995) explored the social interactions among participants in adult day care and concluded that a range of interactions and relationships were essential to the maintenance of a sense of self. Two important studies, Wigg (2007) and Bergland and Kirkevold (2008), both of nursing home residents, illustrate how strongly the intimate and complex relationships between residents add to their wellbeing, positive daily living and personhood. Bergland and Kirkevold highlighted the role of staff in supporting such positive interactions. Ward, Vass, Aggarwal, Garfield, and Cybyk (2008), in their qualitative study of day-to-day relationships in care homes, use their findings around communication and particularly non-verbal communication to highlight the importance of recognising and supporting communication. Not only do such communication opportunities help to sustain relationships, but they illustrate the desire for people with dementia to continue to communicate and engage in reciprocal social relationships.

In their investigation of adult friendships, Spencer and Pahl (2006) draw attention to the notion of 'personal communities'. The authors map the mix of formal and informal relationships, of friendships and family in people's lives and consider how these networks coalesce to support a sense of belonging and identity for the research participants. As our presented case studies illustrate, the onset of dementia can disrupt and even rupture the personal communities of the person with dementia. Interestingly, Spencer and Pahl (2006) draw particular attention to what they describe as 'hidden solidarities' making the point that we should not assume that friendships are associated with particular situations or settings (such as neighbourhoods) and that by focusing on a person's informal personal relationships, a more direct sense of community begins to emerge. This finding points to the value for practitioners (such as nurses and social care workers) in engaging with people with dementia to map their networks, for example by eliciting friendship narratives of the type we present in our first case study.

Eliciting friendship narratives from people with dementia helps us to understand the patterns of closeness and intimacy in their lives, but also how dementia affects these bonds and ties. Such narratives also have the potential to be educative for the practitioner involved, offering insights into the experience of stigma, the management of a social identity and the strategies that people use to maintain the connections that are important to them. Friendship narratives can also reveal a temporal dimension, including a sense of how relationships evolve over time to adapt to challenges and transitions and underline the reciprocity that is so often overlooked in research on dementia, which has been criticized for its narrow focus on received support (Offord et al., 2006). 
The recent rise in more participatory approaches both to research and practice regarding dementia has marked a shift to greater emphasis upon the perspectives and experiences of people with dementia. For example, Keady, Williams, Hughes-Roberts, Quinn, and Quinn (2007) worked alongside Mo and Pat Quinn (a younger person with dementia and her husband) over the course of a year to help develop and visualize [their] personal theory about living with dementia. In the diagram that the couple produced to illustrate the meaning of their lives together with young onset dementia, their relationships and the friendships that had been developed within the ACE Club (a specialist young-onset dementia day service that they attended: see yDavies-Quarrell, the ACE Club, and Keady (2010) for further information) were shown to be pivotal in helping the couple recover a sense of identity and belief in their abilities to cope with the condition. The authors argue that such theory-building diagrams represent a valuable intervention for working with people with early stage dementia, supporting them to map the networks to which they belong and thereby to reinforce a sense of identity.

We now turn to consider two case examples that involve making and maintaining friendships following the onset of dementia. Both cases are based upon first-hand accounts of friendship from people with dementia while signalling the importance of input from 'friendship facilitators', both formal and informal.

\section{Method}

The first of the two case examples in this article is provided by Dr Mike Howorth, a retired orthodontist who lives with Alzheimer's disease. Mike is 80 years old and is employed as the Open Doors Network co-ordinator in Greater Manchester West Mental Health NHS Foundation Trust (GMW). Mike has recently written about his work in this post (Howorth et al., 2011), but in brief it is believed that Mike is the first person with dementia in the UK to be employed by the NHS to enhance and support the development of dementia services, an opportunity that Mike has taken to help people in an 'expert patient' role at the point of diagnosis. However, in this article, Mike is writing in a personal capacity, reflecting his guiding philosophy: 'As a person with dementia, I am hoping to show the importance of friendships and their significance both literally and emotionally.' This narrative was provided by Mike as a written account and at the same time as this article was being developed. The final direction, editing and contents of the case illustration are Mikes and his alone.

The second case is drawn from a local-level evaluation of the 'Friends for Life' peer support project (2010-2011) in Salford, Greater Manchester, UK which formed one of the pilot 'demonstrator sites' commissioned by the Department of Health to inform the implementation of the English National Dementia Strategy (Department of Health, 2009). The 'Friends for Life' peer support group is based upon a neighbourhood structure with seven groups taking place in different parts of the city of Salford. Each group is located in an accessible venue close to public transport. The Friends for Life project is facilitated through Age Concern Salford, a local voluntary sector organization that works extensively with people living with dementia. Each 'Friends for Life' group has a main facilitator, a second paid helper and one or two volunteers available to support those who attend. The local evaluation of the 'Friends for Life' project was conducted by an independent team from the University of Manchester that included some of the co-authors of this paper (RW, SC and JK). The evaluation involved observations in each peer support group, joint discussions 
held with the members and interviews with the staff who run the Friends for Life project and those who facilitate the groups. Each interview and discussion group was recorded and later transcribed. In the second case study illustration we highlight one of the more established groups that has been meeting for a year since March 2010, with most of the attendees coming for much of this time. Ethical approval to conduct the evaluation, from which this case study was taken, was provided by the University of Manchester Ethics Committee in February 2011.

\section{Case Study I. Dr Mile Howorth: my thoughts on friendships}

'Friendship'. When I started thinking about this word, I realized there was more to the meaning than a dictionary definition: that is one person joined to another in mutual benevolence, other than sexual or family love. It's not only about trust, loyalty, disclosure, but also about having a relationship on a level that is more intimate than just spending time with someone. Of course, all my life, I regarded this description as the one that was relevant to me; however, this gradually changed after receiving my diagnosis of Alzheimer's disease. At first, I wanted to include relatives in the definition, and especially my wife, Sue, whom I regard as 'my very best friend'.

I have always maintained that it was Sue who was responsible for getting me to the memory clinic, but she says it was a joint decision. Over the previous couple of years I did have thoughts from time to time of feeling 'a bit down', although I couldn't say I felt depressed, but I did wonder if it could be due to some minor problems in our marriage. None of my friends had mentioned anything untoward in my personality, such as memory or behaviour problems. It was during this period that I went to stay with a friend who had emigrated, and who I hadn't seen for 2 to 3 years. During the intervening period, he had been diagnosed with Alzheimer's disease, although he seemed to be very much how I remembered him. However, I was aware of 'changes' in his personality, which I attributed to his Alzheimer's disease. This had no effect on our friendship; I just felt I wanted to help him cope with his 'problem'.

The reactions that Sue and I had to the actual diagnosis of Alzheimer's disease were quite different; for me, not totally unexpected, due to a family history of dementia, and so not too much of a shock. My feelings towards the medical staff, and consultants particularly, were quite without antagonism or disrespect, probably because of my medical background. After all, everything they did or said was for my future mental wellbeing. On the other hand, for Sue, it really was a shock. Our relationship had deteriorated over the past few years, initially through hearing loss, but latterly through many misunderstandings that we now believe were caused by cognitive impairment. She says the diagnosis tended to make her imagination fly from A (the diagnosis) to $\mathrm{Z}$ (the final outcome).

We sat and talked about it together and about everything in between $\mathrm{A}$ to $\mathrm{Z}$, and decided that we would not only 'fight it' but be very open to our friends about it. We were both conscious of the wretched thought that I could be ending my days in some form of home; very depressing. We made plans that if it became necessary in the future we could change our sitting room into a bed sitter, to keep me in my familiar surroundings for as long as possible. We would take every opportunity to get help and advice and make the most of our lives. My initial concerns were thoughts on how Alzheimer's disease would affect my friends and family (and the possibility of their inheriting the disease), and also how it would affect 
our life styles and what plans would have to be made long-term, e.g. financial and legal, social and domestic.

With regard to friendships, I can share two negative incidents: when a relative was first told of my Alzheimer's disease, he was unable to comment, and in fact turned his head away in an attempt to change the subject. On another occasion, a golfing friend, who knew of my dementia, remarked when I entered the bar 'Hello Mike, do you know where you are?'. I assumed he was being serious, but he may have 'had a few', and was trying to be funny. These two examples reminded me of how much ignorance there is about dementia and how important it is to expect the unexpected, and not to be upset by adverse comments. On the other hand, I don't remember any reassuring comments from friends at this point in time; these were to come later.

Now, 3 years down the line, I'm aware of small discrepancies in my memory. For example, if I haven't understood something, I am unable to work out whether it is because of my hearing ability, or whether it's because of my cognitive problems; or is it a combination of the two? Friends sometimes tell me they do not believe I have Alzheimer's disease; this, I feel, is due to my early diagnosis, and to the principal symptom being mild cognitive impairment, which is not immediately apparent in everyday conversation.

Soon after being informed of my dementia, a post diagnostic group was set up, organized and run by Admiral Nurses (see Box 1). The group comprised about six other new patients and their partners/carers. This gave a degree of hope to know of others in a similar predicament; I felt this was very reassuring. We received a great deal of help in overcoming problems, in my case mostly to do with memory, and in the sort of difficulties we might expect in the future. In this regard, I became particularly friendly with one of the Admiral Nurses, who reassured both me and my wife that we mustn't worry about such things as nursing home problems. Another worry for me, still with ability to reason quite normally, was how Sue would cope. These sessions were very sociable, and encouraged the formation of long-term friendships. I became particularly friendly with a retired doctor, whose wife was coming to the end of her life with dementia; we had long discussions on mental health issues, and it was he who reminded me of the importance of being active, both mentally and physically, and to maintain/increase friendships. To this end, I joined the Alzheimer's Society Quality Research in Dementia (QRD) group (for assessing the quality of research projects for funding) along with finding out, through reading and the internet, as much as I could about the disease from a self-help point of view.

\section{Box I}

Admiral Nurses are specialist dementia care nurses who have a registered mental health nursing qualification and who practice in the community. There are currently over 50 Admiral Nurses in England with plans to develop the service in other localities as well as in other countries of the United Kingdom. Admiral Nurse casework focuses primarily on the needs of the family and its wider network in the support, care and empowerment of a person with dementia. Admiral Nurses are employed in NHS Trusts and/or other host agencies through a partnership arrangement with the national charity 'Dementia UK' (http://www.dementiauk.org/; accessed 20 April 2011) 
Returning to the post-diagnostic group, we were about six to eight couples (user and carer). By chance, one of the carers was a good friend from my golf club, so right from the start I had a sound friendship 'without any effort', his wife being the person with dementia. Obviously, it was easy to communicate with him because of our long-standing friendship, except on anything to do with dementia; he found it very difficult to use this word and to discuss 'dementia matters', whereas I had no problem with this (I still wonder why). As for his wife, she was a very reticent lady, but over time she became much easier to talk to, in spite of her condition. It was fortuitous that the two of us received our diagnoses at approximately the same time. We both continued to play golf and have a social life at our club, as though nothing had changed. The subject of dementia was never mentioned on social occasions, for fear of embarrassing one another and also our friends. Our friendship became much closer as a result of having a new 'problem' in our lives. This relationship made me realize the importance of having friends, not only with people with dementia, but also those without. Over the last 2 or 3 years, I have got to know a number of other people with Alzheimer's disease with whom I can compare our symptoms and talk about our lifestyles.

Some 6 months after diagnosis, I was involved in another post-diagnostic group, but this time just for users; one member left after the first meeting, but another member of the group was very out-going and friendly, and at the end of the course we agreed to meet on a regular basis. Unfortunately, it didn't come about for reasons that I can only guess; perhaps he would be embarrassed to talk and compare notes on a one-to-one basis, or maybe his wife didn't approve.

During the months following diagnosis, I became more and more involved with dementia matters; not only in the medical/research side, but also in meetings and conferences. By now I was an experienced member of the Alzheimer's Society QRD (the Quality Research and Development Consumer Network) and I realized how much more I was using my cognitive abilities. I believe I was doing a lot of the 'right things' to slow down the progress of my Alzheimer's disease such as communicating with other like-minded people, through friendships. Particularly helpful were the 'memory cafes' organized by the local branches of the Alzheimer's Society and Admiral Nurses. More recently, the nature of my friendships changed when I was offered the opportunity to work part-time for GMW. In this situation, my definition of the word 'friendship' is modified to include colleagues: people with whom I would be working, not only staff who work alongside people with dementia in their professional capacity, but also people with dementia at a critical time in their lives. In reaching a decision to accept the post of co-ordinator of the Open Doors Network in GMW, my wife and I agreed quite readily that the work could be very helpful to users. For example, since my diagnosis, I had come to realize through conversations with other carers, that there was a particular need for information and assistance for those newly diagnosed with dementia, whatever its type or cause. It is at this point that I must mention the ease and comfort I have, in conversing with others on dementia related topics; it all seems so natural.

When I finally accepted the position of the Open Doors Network co-ordinator, it became necessary to find the time to do this by giving up some of my retirement pastimes, such as bridge and golf. Of necessity, this meant a change in the nature of my friendships from purely 'social', to forming new friends and friendships as a result of my work. There was, also, a considerable increase in my mental exercise, especially in communicating, which 
could only be helpful to me personally. Being a member of Samaritans, my wife is also very interested in psychological matters and this has been most helpful in our personal relationship.

Inevitably, there will be the loss of a long-standing friendship for reasons not connected with a mental problem, such as a move to some distant location. When the loss of a friendship is due to a reduced intellect by one of the pair, it is to be greatly regretted. I believe there is a moral duty to help an old friend, when they lose their ability to communicate, by keeping in touch for as long as possible. I don't believe I have personally experienced this, but as my dementia worsens, I am sure this will happen, and then I shall be asking myself: 'have I been excluded because of ignorance/stigma by my friends, or am I really losing my ability to communicate?'. I have already noticed, however, that when I'm involved in a discussion in a group, I tend to be sidelined in the conversation. This may be partly due to my poor hearing, or, I wonder, is it due to my reduced cognitive ability, thereby causing a response to be delayed, or even not made at all? I find this makes me anxious or even slightly depressed.

Friendships may come and go; the more interests we have in common, the longer the friendship is likely to last. But in old age, they do have a greater significance.

The contacts that are made between people with similar interests, lead to discussion and mental stimulation. These are the most important factors, in delaying the onset, or slowing the progress, of dementia and, which, in any case, certainly increase the person's well-being. In conclusion, anything that can be done to maintain or increase friendships between people with dementia, as well as with those without the condition, can only be considered as essential for maximum quality of life.

\section{Case Study 2. Friends for Life evaluation}

This particular group meets in a specialist dementia centre (others meet in church halls, libraries and resource centres). The room is bright but formal in its layout. The group members arrive and seat themselves around a centre table and the three facilitators (two paid staff, both female and one male volunteer) organize tea and coffee. The group members chat to each other around the table before the session begins. Each session starts with introductions (mostly this happens if there are new people and visitors) but would always include a welcome and hello slot. The facilitator then moves onto giving out information that includes group updates and news, information from Age Concern and information about events and activities going on in the neighbourhood (most of the groups we visited had established routines like this). One group member explained: 'We've been coming here for a long, long time, the five of us here, but in-between that we've seen several people come and go', and so it seemed that there was a long-standing core group, consisting of four men and one woman.

The information sessions can take some time as members join in and talk about any events or other groups that they have attended. In this group there were a couple of more outspoken individuals, one of whom in particular seemed to be a very important character to the group dynamics. He spoke often, made lots of jokes and generally included everyone around the table. He also engaged in humour and sparring with the facilitator.

The session then moved into a planned activity, this particular week it was a session on 'traditional games' and the facilitators began by talking about games that they used to play and asking the group about their memories of games they had enjoyed. The facilitator then 
got everyone involved in playing a game of bingo, though one person had no interest in playing they were persuaded to be the ball turner.

During interview, the facilitator said that the group sessions were led by the group members and that if members were more interested in chatting and catching up than having a planned activity then the facilitators' would hold back from the organized activity. The group used a lot of humour, and gentle teasing was common between group members themselves and between group members and the facilitators.

The exchanges between group members were often supportive, and they willingly shared information. There were a couple of the men who were quieter, but they still seemed to feel that they could share openly in the group. It appeared more difficult for the only woman in the group to join in and she remained very quiet during the meeting that we observed. However, she had been part of the group for a long time and although other women had joined and moved on, she had chosen to keep returning to this particular group.

Members passed on information to each other about groups they thought the other person might like or talked about things they had tried together, one example was when two members had participated in a curling (a type of bowling) event. The shared experience of having been together through the growth of the group as well as the shared experience of dementia seemed to have value in holding people together, as one of the men in the group commented:

'But as I say, after this three, four months we've been here now I've really looked forward to coming to them, and we can openly, without being ashamed, if that's another word that...Be ashamed of what you're talking about, you're among friends.'

During the meeting there was a chat between some of the men about sport. Two were avid rugby fans and one was an ex-professional footballer. The men bonded over the enjoyment of the sports that they followed. This included teasing and jokes about liking different teams and sports. We found that many of the groups had a core of members who often had built a relationship out of shared histories and experiences. In another, all-male group, most of the men had spent time in the armed forces and this provided common ground for sharing past experiences.

It is important to consider what bonds people together, and although having a shared diagnosis of dementia was integral to the feeling of 'being in the same boat', there were other factors that helped knit the group members together such as the shared interests as described here and possibly the shared gender for the men in the group. The group did not appear to have been as successful for other women who had tried it but dropped out or moved to other groups. By contrast in other groups there was a preponderance of women, perhaps creating a less inviting prospect to the men who tried the group. The female member of the group said of her own experience:

'I enjoy coming meeting everybody, although I'm mostly the only woman that's around, [chuckles] people come and stay a week or a couple of times, and then they stop coming. [...] Oh yes. Yes, I feel comfortable with everyone.'

This quote illustrates that people have different needs from groups such as this and may find various connections that support their continued participation.

The importance of the shared experience of dementia was expressed repeatedly by the group members, and this member described going out to other places but not having the freedom to discuss his concerns with other friends without them becoming tired of 
listening.

'I mean you talk like this and I know we can go to the boozer, we can go to the club, wherever you go and all that, or you might go to shops and all that, and you talk like we're talking in here, and they say oh, give over, you know what I mean? They put you to one side or just say will you give over? But here, with everybody having [...] Not the same complaint like we've got, we've come here and we're all there, we can openly discuss anything that we're having.'

The group members also discussed groups that were not welcoming and one member said that he had joined his local church group but that he did not really feel as though he 'belonged'. Another person said 'They're always clique-ish, church people'. This exchange carried on into a conversation about people 'getting into groups' in all environments. One person stated that it happened at work, and another person agreed and said that it was important to be in a group, in a clique: 'You're in a group, aye, a clique, of course they do. If you weren't in it, it was hard luck wasn't it'.

Such an exchange illustrates the value placed on belonging and the need for social acceptance amongst all people. A diagnosis of dementia raises the risk of social isolation and therefore the early opportunity to become connected to others in a similar situation clearly has huge significance for a person's well-being.

The group also became a space in which to process feelings and experiences relating to their dementias. One man said:

'The worst thing that happened to me basically is when they came along and said you're driving time is over, finished, take your licence off you, you can't drive, and that's the worst thing that happened to me. And it took me a long time to get used to going [...] you're not going just out the door and driving off somewhere, you can't.'

Another group member acknowledged that the same thing had happened to him:

"They did that to me the other week. I only just found out I didn't have a car! They took my licence off $m e$ "

The processing of their experiences led to a discussion about the stigma of having a diagnosis of dementia. One person recalled how his friends who do not have dementia had described him coming to the group:

'They'd say at one time you say you're going to the funny farm. "Are you at the funny farm next week?" Like Saturday or Sunday when I, well, [...] "Where do you mean? Are you going to your meeting?" I said, "funny farm?" They said it like that, yes. But that's what they call it, joke. Like they say [name of old mental hospital] and all that, yes. Funny farm, I said [chuckles]'

The group members agreed on the value of talking about dementia and what it meant, as this exchange between two of the men in the group illustrates

Group member 1 'And it's not brushed under the carpet as my mam would say, you've heard that saying, haven't you?'

Group member 2: 'It's not brushed under the carpet, it's open and it's anything, don't be frightened of it.'

In this group some members did see each other at another Age Concern group, and another couple in the group turned out to have been childhood friends. The group had brought them back together after not seeing each other for nearly 
60 years. Mainly the members only met in this fortnightly group, and the friendships were not generally linked into the rest of their lives but the value placed on the relationships was great.

The friendships are 'facilitated friendships' in the sense that they are brought together for a specific reason: a shared diagnosis of dementia and supported by a facilitator. The reason that the group works is because of the dynamic created by the individuals in it, their sense of belonging and acceptance and the manner in which these relations are fostered by the vital contribution of the facilitator.

The workers we interviewed listed practical tasks such as reminding some attendees of the date and time of the sessions, offering lifts to those who may find it difficult to travel alone and planning activities should the group decide to include a more structured element to their meeting. There was also mention of research in local libraries to find out about the big employers in the district that some of the members had worked for, gathering of information on local events and resources to promote activity beyond the groups themselves and organisation of visits and other administrative activities to support the group.

The facilitators spoke of realizing the need to 'stand back' from the groups, to support rather than lead and the anxieties and uncertainties attached to this co-productive way of working. In some of the groups we observed there were still indicators of a more traditional helper model, with the facilitators making and serving tea, taking decisions over the timings of the group and the introduction of activities and assessing people to discern their suitability for the group.

In each of the groups we visited the members referred to one another as friends and it was clear these friendships flourished because there is shared understanding, through a shared history or because of shared experiences, likes and dislikes. Presenting opportunities to people in the early stages of dementia to make connections with others in a similar position can be life-enhancing. As one member of the group explains:

'It gives you the opportunity to go somewhere and you can enjoy it and it brings out something, it's a question [...] it's alright, it's only once a fortnight. I'd come once a week if I could, I think it'd be better for us to do, but that's not [...] But it's something to look forward to as much as anything else.'

\section{Discussion}

In this paper we have made the case for looking beyond the family as the 'go to' support network that practitioners tend to focus upon in their work with people with dementia. Our friendship case examples have highlighted the immediate post-diagnostic phase and the stigma associated that can make maintenance of relationships difficult. In this section we discuss the case examples presented with a particular emphasis on their implications for practice.

Our first case example was a first-person friendship narrative that offered insights into the subjective experience of friendships for a person living with dementia. It is an account of a 'personal community' and how this evolves following a diagnosis. Eliciting narratives such as this holds much potential for dementia care practice. Such narrative work means taking into account the social worlds of people living with dementia. Our sense of self resides in social relationships and so asking someone to give an account of the relationships they value can reinforce a sense of identity and belonging. Mike's contribution to this paper underlines 
how friendship narratives can support practitioners to recognize the presence and impact of the stigma attached to dementia and the social consequences of receiving a diagnosis. His own role in supporting and assisting others challenges the emphasis in much existing literature and policy upon people with dementia as the passive recipients of care.

It has been argued that the friendships people enter into and the practices they observe as part of these relationships are patterned by considerations that include class, culture, gender and life stage (e.g. Wenger, 2002). The changing landscape of personal relationships in more recent times has led to even greater variance and diversity as a result of the rise of new familial forms, changes to household structures and the increasing numbers of people choosing not to have children. Such diversity has direct implications for dementia care practice at a time when, in many parts of Europe and North America, service provision to older people is receding. As access to formal sources of support tightens it is particularly important to appreciate the broader web of relationships in which people with dementia are involved; the strong and weak ties that exist often locally and the challenges associated with maintaining them following a diagnosis of dementia.

Other recent investigators of personal relationships have been less ready to eschew the impact of neighbourhoods upon personal communities. Work by Clark and Emmel (2009), for instance, has shown the way that neighbourhoods still enable and constrain the formation of social networks (see also Clark, 2009). In our second case example we looked at a group that had been set up as part of a larger neighbourhood model of peer support for people with dementia. Our findings from the evaluation underlined the value of local and accessible opportunities for sociality and support in a context where many participants had lost their driving license as a result of their diagnosis and found travelling over distance by public transport challenging.

Our evaluation took a 'snap-shot' impression of the network of groups that formed the project. Indeed, delays in securing ethical approval to hold discussion groups with the attendees led to a truncated period for fieldwork and a narrow window in which to undertake the work. As such, we were unable to consider how the groups evolved over time, as had been the focus of the research described by Offord et al. (2006). However, our observations and discussions still enabled us to discern many similar patterns and practices within the groups, which underlined that 'people with dementia are able to use and benefit from reflective therapeutic space' (Offord et al., 2006, p. 192). Where our evaluation departed from the existing research on peer support was in our concern to understand also the challenges attached to facilitating such groups for the practitioners involved.

\section{Facilitated friendships}

The peer support model was developed within the disability and mental health movements and is based upon the sharing of support between people, often service users, with shared social and service-related experiences associated with disability and mental illness. The relevance and benefits of this model for people with dementia has only recently been acknowledged in policy in the UK although such groups have existed in some areas for many years (e.g. Quarrell-Davies et al., 2010; Ward, The Scottish Dementia Working Group, \& River, 2010).

Peer support groups involve the creation of a space that might not otherwise exist in the lives of those who attend, both a physical space and a space for collaborative meaning- 
making about dementia, away from the imposition of medicalized definitions of the condition characterized by an emphasis on deficit. What is distinctive about the limited but emerging literature on peer support and dementia is that the role of the practitioner appears to have been whitewashed from the picture, with very little consideration given to the particular skills that facilitating such groups may require.

In our view, this oversight is problematic because, as our evaluation of the Friends for Life project showed, the facilitators do a great deal of important 'behind the scenes' work to enable the groups to function. Our impression from the interviews we carried out was that the facilitators were edging toward a different type of role and set of skills and were beginning to recognize the limitations and sometimes unsuitable nature of the more traditional co-ordinator/helper role associated with service delivery to people with dementia. As one facilitator commented it means OK, we just sit back and let it go along, there's nothing wrong in that, rather than keep, you know, interjecting and you know, re-guiding people down different routes'. But letting go of the more familiar and often directive approach is a challenge, which calls for the facilitators to take a step behind group members, offering a safety net to them as a group and at an individual level, rather than being one step ahead and endeavouring to lead.

With such findings in mind we began to question the term 'peer support' as it seemed to negate this crucial assistive work. In its stead we propose the notion of 'facilitated friendships', which may prove more meaningful to those who participate in such groups and which more explicitly recognizes the role of the practitioner. A focus on facilitated friendships could help to open a debate on the skills required for such a role, create opportunities for sharing good practice and help to reflect more broadly on the implications of the new working culture associated with a citizenship-based model of dementia (Bartlett \& O'Connor, 2010). While our focus in this paper has been upon such a role in the context of the early stages of dementia, existing literature on care homes and other institutional settings also underlines the significance of friendship facilitation. For example, Bergland and Kirkevold (2008) noted that where care-workers had mastered the facilitator role they were better placed to support the social networks of residents, but found that often staff paid little attention to creating opportunities for such networks to be maintained.

\section{Conclusions}

Far from being an isolated addition to the debate on dementia, the focus on friendships represents a broader shift in thinking and theorizing associated with the condition. It comes at a time when the model of service delivery and the role of the practitioner are being rewritten, with a growing emphasis on co-productive working and the need to encompass the more diffuse nature of support and resources that exist for people with dementia. While much of these resources may rest within their local community, there is a need to break down the existing barriers in order to support better access for people with dementia. The big question now is whether this broader range of resources and the personal communities of people with dementia can coalesce to create a sense not only of being supported but of belonging and inclusion. Such a question points to an evolving role for practitioners and the on-going significance of their expertise as advocates and facilitators.

As we have argued in this paper participatory approaches are key to these developments. The direct involvement and action of people with dementia fostered by the activities of friendship facilitation are already beginning to produce the early signs of collective 
agency, as people with dementia work together in setting the terms of engagement and exercising greater control over how dementia is understood and responded to.

\section{Funding}

The evaluation from which Case Study 2 was taken was commissioned by Manchester Primary Care Trust.

\section{Notes}

1. The term 'facilitated friendships' refers to friendships that have grown out of situations where people have been brought together, for example in support groups, and where relationships have been fostered by a facilitator (such as a dementia practitioner).

2. A user-led network of people with dementia living in Salford.

3. A peer support pilot project for people with dementia.

\section{References}

Bartlett, R., \& O'Connor, D. (2010). Broadening the dementia debate: Towards social citizenship. Bristol: Policy Press.

Bergland, Å., \& Kirkevold, M. (2008). The significance of peer relationships to thriving in nursing homes. Journal of Clinical Nursing, 17, 1295-1302, DOI: 10.1111/j.1365-2702.2007.02069.x.

Blieszner, R., \& Shifflett, P. A. (1990). The effects of Alzheimer's disease on close relationships between patients and caregivers. Family Relations, 39, 57-62.

Charlesworth, G., Tzimoula, X., Higgs, P., \& Poland, F. (2007). Social networks, befriending and support for family carers of people with dementia. Quality in Ageing and Older Adults, 8(2), 37-44.

Clark, A. (2009). From neighbourhood to network: A review of the significance of neighbourhood in studies of social relations. Geography Compass, 3, 1559-1578.

Clark, A., \& Emmel, N. (2009). Connected Lives: Methodological challenges of researching networks, neighbourhoods and communities. Qualitative Researcher, 11, 9-11.

Clarke, C. L., Keady, J., Wilkinson, H., Gibb, C. E., Luce, A., \& Cook, A., et al. (2010). Dementia and risk: Contested territories of everyday life. Journal of Nursing and Healthcare of Chronic Illness, 2, $102-112$.

Davies-Quarrell, V., the ACE Club, \& Keady, J. (2010). The ACE approach: Promoting well-being and peer support for younger people with dementia. Journal of Mental Health Training, Education and Practice, 5(3), 41-50.

de Boer, M. E., Hertogh, C. M. P. M., Droes, R.-M., Riphagen, I. I., Jonker, C., \& Eefsting, J. A. (2007). Suffering from dementia - the patient's perspective: A review of the literature. International Psychogeriatrics, 19, 1021-1039.

Department of Health (2009). Living Well with Dementia: A National Dementia Strategy. London: Department of Health.

Heaphy, B. (2009). The storied and complex lives of older GLBT adults: Choice and its limitations in older lesbian and gay narratives of relational life. Journal of GLBT Family Studies, 5, 119-138.

Howorth, M., Riley, C., Drummond, G., \& Keady, J. (2011). The Open Doors Network: A pioneering scheme. Journal of Dementia Care, 19(3), 4-5.

Keady, J., Williams, S., Hughes-Roberts, J., Quinn, P., \& Quinn, M. (2007). 'A Changing Life': Coconstructing a personal theory of awareness and adjustment to the onset of Alzheimer's disease. In M. Nolan, E. Hanson, G. Grant, \& J. Keady (Eds.), User participation research in health and social care: Voices, values and evaluation (pp. 69-88). Maidenhead: Open University Press/McGrawHill. 
Kutner, N. G., Brown, P. J., Stavisky, R. C., Clark, W. S., \& Green, R. C. (2000). Friendship interactions and expression of agitation among residents of a dementia care unit: Six month observational data. Research on Aging, 22, 188-205.

Lilly, M. L., Richards, B. S., \& Buckwalter, K. C. (2003). Friends and social support in dementia caregiving: Assessment and intervention. Journal of Gerontological Nursing, 29, 1-29.

Offord, R. E., Hardy, G., Lamers, C., \& Bergin, L. (2006). Teaching, teasing, flirting and fighting: A study of interactions between participants in a psychotherapeutic group for people with a dementia syndrome. Dementia, 5, 167-195.

Roseneil, S. (2004). Why we should care about friends: An argument for queering the care imaginary in social policy. Social Policy in Society, 3, 409-419.

Roseneil, S., \& Budgeon, S. (2004). Cultures of intimacy and care beyond the family: Personal life and social change in the early twenty-first century. Current Sociology, 52, 135-159.

Snyder, L., Quayhagen, M. P., Shepherd, S., \& Bower, D. (1995). Supportive Seminar Group: An intervention for early stage dementia patients. The Gerontologist, 35, 691-695.

Spencer, L., \& Pahl, R. (2006). Rethinking friendships: Hidden solidarities today. Princeton, NJ: Princeton University Press.

Ward, R., The Scottish Dementia Working Group, \& River, L. (2010). Between participation and practice: Inclusive user involvement and the role of practitioners. In J. Keady, \& S. Watts (Eds.), Mental health and later life: Delivering an holistic model for practice. London: Routledge.

Ward, R., Vass, A. A., Aggarwal, N., Garfield, C., \& Cybyk, B. (2008). A different story: Exploring patterns of communication in residential dementia care. Ageing and Society, 28, 629-651.

Weeks, J., Heaphy, B., \& Donovan, C. (2004). Same sex intimacies: Families of choice and other life experiments. London: Routledge.

Wenger, G. C. (2002). The special role of friends and neighbours. Journal of Aging Studies, 4, 149-169.

Weston, K. (1991). Families We Choose. New York: Columbia University Press.

Wigg, J. M. (2007). A culture of dementia: Examining interpersonal relationships between elders with dementia. PhD dissertation, Brandeis University.

Williams, B., \& Roberts, P. (1995). Friends in passing: Social interaction at an adult day care center. International Journal of Aging and Human Development, 41, 63-78.

Richard Ward, DipSW, PhD is a Project Worker in Ageing and Mental Health for the University of Manchester and the Greater Manchester West Mental Health NHS Foundation Trust. His interests lie in exploring the everyday lives of people living with dementia. He is currently leading a study investigating the provision of hairdressing services and personal grooming in dementia care settings; and is exploring how carers of people with dementia engage with their local neighbourhoods and the support networks that exist therein.

Mike Howorth, LDS, RCS Eng practiced as a general dental practitioner, but following retirement he was diagnosed with Alzheimer's disease, in 2007. For the last 18 months he has been employed part-time with Greater Manchester West Mental Health Trust, as the Open Doors Facilitator, helping patients with a recent dementia diagnosis. He is involved with the Friendships Support Group along with various research projects.

Heather Wilkinson, PCGE, PhD is a Co-Director of the Centre for Research on Families and Relationships and the Director of Research and Knowledge Exchange for the School of Health in Social Science, University of Edinburgh. Her research interests focus on the experience of people with dementia and for people with a learning disability and dementia, and improving their care experience. Much of her work focuses on developing 
methods for including people with dementia in research and policy and she was a founder member of the Scottish Dementia Working Group. Recent publications include Risk and dementia care (2011, Jessica Kingsley) and Night time care: Providing care through the night in residential and care homes (2010, Jessica Kingsley).

Sarah Campbell is a Research Associate within the Dementia and Ageing Research team within the School of Nursing, Midwifery and Social Work at the University of Manchester. She is currently working on a project exploring the role of hairdressing and bodywork in the everyday lives of people with dementia. As a part of this study she is undertaking her $\mathrm{PhD}$ exploring masculinity, embodiment and bodywork in dementia care. Her particular research interests are in the body and embodiment; dementia and identity; and the subjective experiences of people with dementia.

John Keady, PhD, RMN, RNT is Professor of Older People's Mental Health Nursing, a joint appointment between The University of Manchester and the Greater Manchester West Mental Health NHS Foundation Trust. He is founding and co-editor of 'Dementia: The International Journal of Social Research and Practice'. 